\title{
COMMENT
}

\section{Early career investigator highlight}

\author{
Anne E. Berens $\mathbb{D}^{1,2}$ \\ Pediatric Research (2019) 86:682; https://doi.org/10.1038/s41390-019-0584-4
}

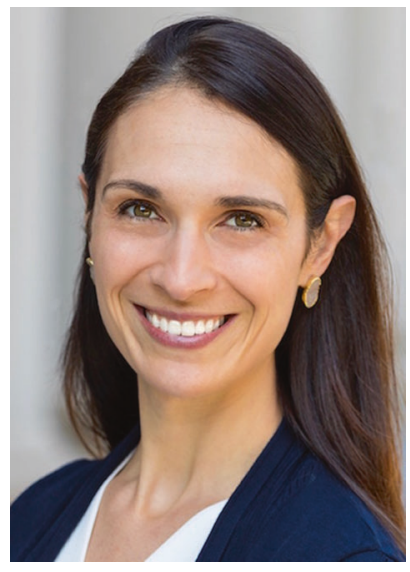

I grew up outside of Boston, Massachusetts. My mom did immigration policy research, and dad was an economist who worked with American Indian leaders on economic development and indigenous governance initiatives. I grew up with an ideal of how researchers, when at their best, could partner with people excluded from dominant power structures and inform policy change. Medical school really did not dawn on me until late in college. As a senior at Stanford, I had become interested in global health, and after graduation I moved to Rwanda to work with Partners In Health. I had great physician mentors there including Drs Henry Epino and Sara Stulac, who influenced my decision to go to medical school. Returning to Boston, I did premedical courses by extension and gained some early research assistance experience with Dr Theresa Betancourt in her Research Program on Children and Early Adversity. I then took one more detour to pursue public health training in London with support from a Marshall Scholarship before starting medical school.

As a medical student at Harvard, I met my most formative research mentor to date, $\mathrm{Dr}$ Charles A. (Chuck) Nelson. At his Laboratories of Cognitive Neuroscience at Boston Children's Hospital, I developed my interest in how early developmental environments, including adverse exposures structured by social inequities and historical injustices, impact child health and wellbeing. I did 2 years of full-time research during medical school, having two children of my own and completing a fellowship at Harvard's Center on the Developing Child. I then matched into Pediatrics residency at UCSF, and we moved west where my partner had started a new company. I am now completing my final year of residency and preparing to begin as a Fellow in Developmental-Behavioral Pediatrics at Stanford in 2020.

I suppose my advice to others in earlier stages of training is that there is no "one way" to do academic medicine. Unconventional careers have their own benefits and costs. Fitting together the puzzle pieces of family, work, and service sometimes requires complicated geometry, and only you can know which choices make sense among the options and constraints at each juncture. Likewise, there is no "good time" to have kids in medicine, since younger trainees sometimes ask me; it will always be hard. But when we are lucky, we get to influence which pieces become part of our life's puzzle to build a picture we value. Academic pediatrics can certainly be a richly meaningful piece.

\section{ADDITIONAL INFORMATION}

Competing interests: The author declares no competing interests.

Publisher's note Springer Nature remains neutral with regard to jurisdictional claims in published maps and institutional affiliations.

${ }^{1}$ Department of Pediatrics, University of California San Francisco, San Francisco, CA, USA and ${ }^{2}$ Children's Hospital Boston, Boston, MA, USA Correspondence: Anne E. Berens (anne.berens@ucsf.edu)

Received: 3 September 2019 Accepted: 13 September 2019

Published online: 25 September 2019 